\title{
Layered Manufacturing of Nanocrystalline Copper Parts Using Pulse Jet Electrodeposition and its Mechanical Properties
}

\author{
Hui Fan ${ }^{1, *}$, Yangpei Zhao ${ }^{2}$, Jie Jiang ${ }^{3}$, Shankui Wang ${ }^{1}$, Zhijing Li ${ }^{1}$ \\ ${ }^{1}$ School of Mechanical and Electrical Engineering, Jiangsu Normal University, Xuzhou, 221116, \\ China \\ ${ }^{2}$ Jiangsu Vocational Institute of Architectural Technology, Xuzhou, 221116, China \\ 3 Jiangsu Key Laboratory of 3D Printing Equipment and Application Technology, Nantong Institute of \\ Technology, Nantong, 226002, China \\ "E-mail: xzfanhui@163.com
}

doi: $10.20964 / 2020.09 .81$

Received: 16 May 2020 / Accepted: 11 July 2020 / Published: 10 August 2020

\begin{abstract}
A new type of layered manufacturing technology that combines the jet electrodeposition method and a rapid prototyping concept is presented. The manufacturing method adopts multilayer scanning electrodeposition using an electrolyte jet to fabricate a micro-metallic part with a nanocrystalline microstructure, which simplifies three-dimensional processing. The research results showed that key parameters, including the current density, applied voltage, nozzle diameter and jet speed, impacted the forming process and deposition quality. The effective current density was observed to reach $350 \mathrm{~A} / \mathrm{dm}^{2}$, at which point nanocrystalline grains with sizes from $30-50 \mathrm{~nm}$ were obtained. It was found that the application of an optimized applied voltage, nozzle diameter, current density and jet velocity increased the forming speed and improved the mechanical performance of the finished parts. A group of nanocrystalline copper parts with a good shape and mechanical properties was produced using optimized parameters with the jet electrodeposition method.
\end{abstract}

Keywords: Layered manufacturing; copper parts; jet electrodeposition; nancrystalline material

\section{$\underline{\text { FULL TEXT }}$}

(C) 2020 The Authors. Published by ESG (www.electrochemsci.org). This article is an open access article distributed under the terms and conditions of the Creative Commons Attribution license (http://creativecommons.org/licenses/by/4.0/). 